\title{
Management of Culprit and Non-Culprit Lesions in Acute Coronary Syndrome
}

\author{
Renáta Gerculy, Noémi Mitra, Evelin Szabó, Diana Opincariu, Monica Chițu, Imre Benedek
}

Center of Advanced Research in Multimodality Cardiac Imaging, Cardio Med Medical Center, Târgu Mureș, Romania

\section{CORRESPONDENCE}

\section{Renáta Gerculy}

Str. 22 Decembrie 1989 nr. 76

540124 Târgu Mures, Romania

Tel: +40 265217333

E-mail: gerculy_renata@yahoo.com

\section{ARTICLE HISTORY}

Received: September 19, 2020

Accepted: November 26, 2020

Published online February 20, 2021
Noémi Mitra • Str. 22 Decembrie 1989 nr. 76, 540124 Târgu Mureș, Romania. Tel: +40 265217 333, E-mail: mitranoemi@gmail.com

Evelin Szabó • Str. 22 Decembrie 1989 nr. 76, 540124 Târgu Mureș, Romania. Tel: +40 265217 333, E-mail: szaboevelin22@yahoo.com

Diana Opincariu • Str. 22 Decembrie 1989 nr. 76, 540124 Târgu Mureș, Romania. Tel: +40 265217333 E-mail: diana.opincariu@yahoo.ro

Monica Chițu • Str. 22 Decembrie 1989 nr. 76, 540124 Târgu Mureș, Romania. Tel: +40 265217 333, E-mail: iulia.chitu@yahoo.com

Imre Benedek • Str. 22 Decembrie 1989 nr. 76 , 540124 Târgu Mureș, Romania. Tel: +40 265217 333, E-mail: imrebenedek@yahoo.com

\begin{abstract}
Multivessel coronary artery disease, defined by the presence of a significant stenosis $(\geq 50 \%$ diameter) in two or more epicardial coronary vessels, usually occurs in more than $50 \%$ of patients with ST-segment elevation myocardial infarction. The latest guidelines indicate revascularization of the non-culprit artery with a recommendation of class IIB. However, the management of non-culprit lesions in patients with acute coronary syndrome is still a matter of debate. This article presents the most recent concepts related to the management of culprit and non-culprit coronary lesions, based on advanced imaging approaches, in order to identify high-risk patients and prevent further acute coronary syndromes.
\end{abstract}

Keywords: multivessel coronary artery disease, culprit plaques, imaging techniques, $\mathrm{PCl}$

\section{INTRODUCTION}

Acute coronary syndrome (ACS) is still the leading cause of death globally despite the major improvements in interventional and pharmacological therapy of atherosclerotic heart disease in the last decade. ACSs are traditionally represented by three clinical entities including acute myocardial infarction with or without ST-segment elevation (STEMI, NSTEMI), unstable angina, and sudden coronary death. The main mechanism of producing this spectrum of coronary heart diseases develops from the presence of one or more underlying intra-luminary atherosclerotic plaques with thrombotic complications. In addition, there are some rare causes, such as coronary artery dissection, arteritis, myocardial bridging, thrombembolism, or coronary vasospasm, without other evident coronary artery disease. An atherosclerotic plaque rupture leads to acute myocardial infarction, due to total (STEMI) or partial occlusion (NSTEMI) of the vessel. In case of multiple obstructive coronary lesions, the identification of the one considered to be responsible for the acute coronary event (culprit) is essential to conduct proper treatment, drawing attention to the risk of complications treating a coronary artery with no plaque rupture (non-culprit). Non-culprit lesions in the setting of an ACS are also highly investigated. There are controversial opinions regarding the management of cul- 
prit and non-culprit lesions in the acute phase of a coronary event.

Noninvasive cardiac imaging techniques, including coronary computed tomography angiography (CCTA), magnetic resonance imaging (MRI), stress echocardiography, and echocardiography, play an important role in identifying patients at high risk for ACS. However, for patients with ACS considered at very high risk, the recommended strategy is immediate invasive approach, performed within 2 hours of hospital admission. Invasive coronary angiography (ICA), combined with modern imaging techniques including optical coherence tomography (OCT) and intravascular ultrasound (IVUS), are useful methods in identifying the anatomical characteristics of the coronary tree but they do not offer information about the hemodynamic consequences of the detected stenosis. The completeness of revascularization, especially in multivessel coronary artery disease, should be decided after evaluation of the functional significance of all lesions (particularly the nonculprit stenosis), left ventricular function, hemodinamical status, age, and comorbidities. ${ }^{1}$

\section{INVASIVE IDENTIFICATION METHODS OF CORONARY PLAQUE LESIONS}

When multivessel obstruction is detected, the culprit lesion is defined as the lesion whose appearance is associated with the ECG changes, or as the lesion with the most obstructive luminal narrowing visible by coronary angiography. Therefore, endothelial dysfunction, elevated sympathetic activity, and its predisposition to thrombosis have a considerable impact on the blood flow dynamics of non-culprit lesions during myocardial infarction. ${ }^{2}$ Intraluminal obstruction below $70 \%$ visible on CCTA or ICA in the coronary arteries are considered non-critical lesions, while critical lesions are defined by a narrowing larger than $70 \%$ of the lumen. However, ICA cannot reliably evaluate the functional severity of these lesions; furthermore, vulnerability features suggesting an increased risk of an acute ischemic event cannot be identified by this method.

The invasive functional assessment of the stenosis using fractional flow reserve (FFR) during the acute phase of an ACS is considered a reliable method to evaluate the ischemia in order to guide the percutaneous treatment. The safety and efficacy of FFR is shown by several randomized clinical trials. However, normal FFR values $(>0.80)$ can lead astray due to submaximal hyperemia and incomplete response to adenosine. ${ }^{3}$ Therefore, an alternative to FFR is iFR, performed in the so-called "wave-free period" in diastole. iFR is not influenced by intravascular pressure alterations, can be performed wihout hyperemic stimulation, and is independent from adenosine response. Several randomized trials established FFR as the gold standard to assess a high-risk coronary artery lesion, ${ }^{4-8}$ but other trials considered iFR to be non-inferior or even equivalent to FFR. ${ }^{9,33}$ It is important to highlight that according to van de Hoeven et al., non-culprit coronary artery flow reserve could be overestimated in the setting of STEMI due to altered hemodynamic forces. ${ }^{10}$ However, the FFR-guided estimation of significant coronary artery stenoses compared to visual angiographic assesment leads to changes in decision-making for coronary intervention. ${ }^{8}$

Intravascular imaging techniques, including IVUS, OCT, or near-infrared spectroscopy (NIRS), are useful in detecting clinically relevant stenoses and high-risk atherosclerotic plaques. The position of the culprit lesion is determined by making cross-sectional images of the coronary arteries. The diagnostic accuracy of the mentioned techniques showed inferiority to physiological evaluation with FFR or even iFR. Similar studies showed a relatively high negative predictive value; however, a low positive predictive value indicates that IVUS and OCT detect plaque ruptures in aproximately $50 \%$ of STEMI. ${ }^{8,11}$

CCTA-derived plaque characteristics, also named markers of vulnerability, including low-attenuation plaque, positive remodeling, the "napkin-ring" sign, and spotty calcification, carry predictive value for further adverse cardiac outcomes. ${ }^{12}$ In the study by Myung et al., culprit lesions in ACS were more frequently observed in the left anterior descending artery, with more severe stenosis, showing a higher incidence of vulnerability markers than non-culprit ones. Additionally, with a more severe degree of stenosis, there was a higher incidence of adverse plaque characteristics (APC) and worse hemodynamic parameters. ${ }^{13-15}$ The identification of culprit lesions with the use of advanced imaging techniques, such as CCTA and FFR, could be useful in the risk stratification of patients and in the prediction of major cardiac events. ${ }^{16}$ Furthermore, CT-FFR, developed by Taylor $e t$ al., offers an approximated value of fractional flow reserve from standard coronary computed tomography images using advanced computational modeling of fluid dynamics. This technology has higher specificity and positive predictive value compared to standard CCTA and is being considered a "gatekeeper" strategy to the catheterization laboratory due to the potential rapid evaluation, noninvasive approach, and cost-effectiveness. ${ }^{8,12,17}$ As previously described, functionally significant, lesionspecific ischemia is considered at a CT-FFR value $\leq 0.80$. Furthermore, von Knebel Doeberitz et al. ${ }^{12}$ demonstrated that CT-FFR has higher discriminatory value over CCTA 
and plaque markers, offering useful information regarding risk stratification. Additionally, Duguay et al. described CT-FFR as a better predictor of stenosis grade than ICA for the identification of further major adverse cardiovascular events (MACE) in the setting of non-culprit coronary lesions in ACS. ${ }^{18,32}$

\section{REVASCULARIZATION STRATEGY: COMPLETE OR NOT?}

It is still unclear whether complete revascularization in multivessel coronary disease brings benefits or reduces the risk of future acute cardiovascular events. It is also still questionable whether complete revascularization compared with culprit-lesion-only percutaneous coronary intervention (PCI) has effects on the size of the affected myocardial territory, on left ventricular function, and on remodeling. There are several studies published in the last few years, which investigated the outcome of these two alternatives of coronary revascularization approach.

In a randomized trial, the DANAMI-3-PRIMULTY substudy compared FFR-guided revascularization to culprit vessel-only PCI in patients with STEMI. They also investigated the size of infarction, left ventricular (LV) ejection fraction, and $L V$ remodeling after the two types of revascularization strategy. They included 280 patients, 136 with culprit-only and 144 with complete FFR-guided intervention therapy. Revascularized patients underwent baseline CMR scans and repeated scanning 90 days later to reevaluate LVEF, LV volumes, and infarction size. Their results showed that complete FFR-guided revascularization in patients with STEMI and multiple obstructive coronary stenoses is not related to the size of affected myocardium, LV function, or remodelation compared with culprit-only PCI. However, the DANAMI-3-PRIMULTI trial demonstrated the benefits of deferred FFRguided complete revascularization, which was associated with the presence of 3-vessel disease and at least one non-culprit lesion with $\geq 90 \%$ stenosis. In these cases, FFR-guided complete revascularization significantly reduced adverse cardiac events from $41 \%$ to $8 \%$, but the difference related to mortality and reinfarction remained nonsignificant. ${ }^{4,19}$

Futhermore, the Compare-Acute study randomly assigned 885 patients with STEMI and multivessel obstructive coronary disease who had undergone primary PCI of the culprit artery and complete FFR-guided revascularization in a ratio of $1: 2$. Accordingly to the results, the risk of composite cardiovascular outcome was lower among patients who had undergone FFR-guided complete revascu- larization of non-infarct-related lesions and culprit lesions as well. 6

The COMPLETE trial, published in 2019, used a sample of 4,041 patients with STEMI and multivessel coronary artery disease. The patients were randomized into two different groups: 2,016 patients who underwent complete revascularization including all significant coronary lesions, and 2,025 patients with culprit lesion-only PCI revascularization strategy. The staged non-culprit revascularizations for STEMI patients were considered within 72 hours during the index hospitalization after successful culprit-lesion PCI. After a 3-year follow-up period, cardiovascular death and myocardial infarction were significantly lower in the group of patients who underwent complete revascularization $(\mathrm{p}=0.004)$. Furthermore, the final results of the trial showed that among patients with STEMI and multivessel coronary artery disease a strategy of complete revascularization resulted in a $26 \%$ lower risk of death from cardiovascular causes or repeated myocardial infarction, compared with culpritlesion-only PCI. ${ }^{20}$

A recent collaborative meta-analysis, assessing 11 nonrandomized studies and 5,850 patients, investigated the outcome of multivessel PCI compared with culprit-only PCI in patients admitted for STEMI, complicated with cardiogenic shock and with multivessel disease. Despite the elevated risks of cardiogen shock for poor outcome, the emergency revascularizaton of culprit and non-culprit coronary arteries seems to not influence neither the short-, nor the long-time survival of these patients. According to this study, there were no differences in cardiovascular death, reinfarction, or reduction of repeated revascularization. ${ }^{4}$ Similarly, an updated meta-analysis of 14 studies by Amartya et al. demonstrated no significant difference in shortor long-term mortality between patients with multivessel PCI (MV-PCI) and culprit lesion-only PCI (CL-PCI) associated with cardiogenic shock. ${ }^{5}$

The CULPRIT-SHOCK trial by Thiele et al. evaluated the clinical outcomes of patients with acute myocardial infarction associated with cardiogenic shock and multivessel coronary artery disease one year after the acute event, after two different revascularization strategies: culpritlesion-only PCI or immediate multivessel revascularization. ${ }^{20}$ They also compared the need for renal replacement therapy in the first 30 days after PCI, and they recorded such an event in $11.6 \%$ of the patients in the culprit-only PCI group and $16.4 \%$ in the multivessel-PCI group. Furthermore, the rate of composite death, recurrent infarction, or acute heart failure needing reshospitalization did not differ significantly between the two groups. ${ }^{22}$ 
TABLE 1. Characteristics and outcomes of the most recent studies related to $\mathrm{PCl}$ of culprit and non-culprit lesions during ACS

\begin{tabular}{|c|c|c|c|c|c|c|c|}
\hline Study name & Authors & $\begin{array}{l}\text { Patients } \\
\text { enrolled }\end{array}$ & ACS event & $\begin{array}{l}\text { Complete } \\
\text { revascular- } \\
\text { ization }\end{array}$ & $\begin{array}{l}\text { Culprit-only } \\
\text { revascular- } \\
\text { ization }\end{array}$ & $\begin{array}{l}\text { Follow-up } \\
\text { period }\end{array}$ & Outcome (Mortality) \\
\hline $\begin{array}{l}\text { DANAMI-3-PRIMULTI } \\
\text { substudy }\end{array}$ & Kasper et al. & 280 & STEMI & 144 & 136 & 90 days & Superiority of deferred MV-PCI \\
\hline COMPLETE trial20 & Shamir et al. & 4,000 & STEMI & 2,016 & 2,025 & 3 years & Superiority of complete $\mathrm{PCl}$ \\
\hline $\begin{array}{l}\text { Meta-analysis of } 11 \text { non- } \\
\text { randomized studies } 5\end{array}$ & Dhacal et al. & 5,850 & $\begin{array}{l}\text { STEMI + } \\
\text { cardiogenic } \\
\text { shock }\end{array}$ & 1,157 & 4,693 & $\begin{array}{l}\text { In-hospital to } 5 \\
\text { years }\end{array}$ & No differences \\
\hline CVLPRIT- trial23 & Anthony et al. & 296 & STEMI & 150 & 146 & $\begin{array}{l}12 \text { months to } \\
5,6 \text { years }\end{array}$ & Superiority of complete $\mathrm{PCl}$ \\
\hline CULPRIT-SHOCK trial22 & Thiele et al. & 706 & $\begin{array}{l}\text { AMI + } \\
\text { cardiogenic } \\
\text { shock }\end{array}$ & 355 & 351 & $\begin{array}{l}30 \text { days and } 1 \\
\text { year }\end{array}$ & No differences \\
\hline Compare-Acute trial ${ }^{6}$ & Smits et al. & 885 & STEMI & 295 & 590 & $\begin{array}{l}30 \text { days, } 12,24 \\
\text { and } 36 \text { months }\end{array}$ & Superiority of complete $\mathrm{PCl}$ \\
\hline
\end{tabular}

Similarly, the CvLPRIT study analized the rate of MACE after a 12-month period of follow-up in patients with complete versus infarct-related-only revascularization at the index admission. The rate of MACE involving all-cause death, recurrent myocardial infarction, heart failure, and ischemia-driven revascularization was significantly lower in the complete revascularization group at 12 months and even after a median of 5.6 years of follow-up. ${ }^{23}$

\section{DISCUSSION}

The conflicting data in the literature regarding to revascularization strategy and the difficulty of decision-making related to culprit-only or multivessel PCI in acute coronary syndromes draws attention to the importance of this topic. However, the estimated severity of non-culprit lesions is often exaggerated due to hemodynamic phenomenons such as vasoconstriction, relative vasodilatation of the normal vessels, and intraprocedural changes in hemodynamics. Furthermore, the levels of catecholamine and other hormones with vasocontrictive effect (serotonine, endotheline, thromboxan, and angiotensin) are elevated among STEMI patients; also, increased oxidative stress is lowering the vasodilatator effect of nitric oxide, adenosine, and prostacycline. ${ }^{2,24,25}$ Moreover, it should be emphasized that MV-PCI increases the complexity of the procedure, while also increasing the risk of myocardial injury and further hemodynamic deterioration from distal embolization, acute vessel occlusion, intrastent thrombosis, or loss of sidebranch. ${ }^{6,26}$ Additionally, the minimal clinical benefit of MV-PCI in the acute phase of ACS can lead to unnecessary prolongation of PCI time, with fatal effects in hemodinamically instable patients. ${ }^{5}$
On the other hand, it is still unclear how early complete revascularization in multivessel coronary artery disease patients could lead to better outcome in long-term followup. Probably its major role is related to the improvement of collateral flow to the peri-infarcted myocardial territory due to profilactic management of the non-infarct-related arteries. ${ }^{27}$ Additionally, MV-PCI of non-culprit arteries may theoretically limit infarct size and preserve LV function, both of which are associated with improved survival in patients with ACS.

However, FFR remains the gold standard for the evaluation of the functional relevance of coronary artery stenosis. ${ }^{28,29}$ In a group of STEMI patients with multivessel disease, revascularized with culprit-only PCI, FFR measured in the non-culprit lesions immediately after successful primary PCI showed a nonlinear and inverse risk continuum of MACE. ${ }^{30,31,34,35}$

\section{CONCLUSION}

Our aim was to evaluate how the management of culprit and non-culprit lesions could improve ACS patient outcomes, both on short and long term after the acute event. Summarizing the most recent literature findings we may conclude that decision-making regarding culprit and non-culprit plaque management should be performed by integrating advanced cardiac imaging techniques. FFR investigation remains the gold standard for evaluating the functional relevance of coronary stenoses. FFR-guided complete revascularization of multivessel coronary artery disease in the acute phase of ACS could improve shorttime outcomes, but long-time benefits of this strategy are still unproven. 


\section{CONFLICT OF INTEREST}

\author{
Nothing to declare.
}

\section{ACKNOWLEDGEMENT}

This research was supported via the research grant no. 103544/2016, contract number 26/01.09.2016, entitled "Increasing the research capacity in the field of vulnerable plaque imaging, based on advanced nanoparticles, fusion imaging and computational simulation - PlaqueImage", financed by the Romanian Ministry of European Funds, the Romanian Government and the European Union.

\section{REFERENCES}

1. Neglia D, Rovai D, Caselli C, et al. Detection of Significant Coronary Artery Disease by Noninvasive Anatomical and Functional Imaging. Circ Cardiovasc Imaging. 2015;8: e002179.

2. Dönmez E, Koç M, Şeker T, İçen YK, Çayli M. The assessment of non culprit coronary artery lesions in patients with ST segment elevated myocardial infarction and multivessel disease by control angiography with quantitative coronary angiography. Int J Cardiovasc Imaging. 2016;32:1471-1476.

3. Montone RA, Meucci MC, Niccoli G. The management of non-culprit coronary lesions in patients with acute coronary syndrome. Eur Heart $J$ Suppl. 2020;22:L170-L175.

4. Lønborg J, Engstrøm T, Kelbæek H, et al. Fractional Flow Reserve-Guided Complete Revascularization Improves the Prognosis in Patients With STSegment-Elevation Myocardial Infarction and Severe Nonculprit Disease: A DANAMI 3-PRIMULTI Substudy (Primary PCl in Patients With ST-Elevation Myocardial Infarction and Multivessel Disease: Treatment of Culprit Lesion Only or Complete Revascularization). Circ Cardiovasc Interv. 2017;10: e004460

5. Kundu A, Sardar P, Kakouros N, et al. Outcomes of multivessel vs culprit lesion-only percutaneous coronary intervention in patients with acute myocardial infarction complicated by cardiogenic shock: Evidence from an updated meta-analysis. Catheter Cardiovasc Interv. 2019;94:70-81.

6. Smits PC, Abdel-Wahab M, Neumann F-J, et al. Fractional Flow ReserveGuided Multivessel Angioplasty in Myocardial Infarction. N Engl J Med. 2017;376:1234-1244.

7. Park J, Lee JM, Koo B-K, et al. Relevance of anatomical, plaque, and hemodynamic characteristics of non-obstructive coronary lesions in the prediction of risk for acute coronary syndrome. Eur Radiol. 2019;29:61196128.

8. Mathew RC, Gottbrecht M, Salerno M. Computed Tomography Fractional Flow Reserve to Guide Coronary Angiography and Intervention. Interv Cardiol Clin. 2018;7:345-354.

9. Götberg M, Christiansen EH, Gudmundsdottir IJ, et al. Instantaneous Wave-free Ratio versus Fractional Flow Reserve to Guide PCl. N Engl J Med. 2017;376:1813-1823.

10. Lee JM, Choi G, Koo B-K, et al. Identification of High-Risk Plaques Destined to Cause Acute Coronary Syndrome Using Coronary Computed Tomographic Angiography and Computational Fluid Dynamics. JACC Cardiovasc Imaging. 2019;12:1032-1043.

11. Mintz GS, Guagliumi G. Intravascular imaging in coronary artery disease. Lancet. 2017;390:793-809.

12. von Knebel Doeberitz PL, De Cecco CN, Schoepf UJ, et al. Impact of Coronary Computerized Tomography Angiography-Derived Plaque Quantification and Machine-Learning Computerized Tomography Fractional Flow Reserve on Adverse Cardiac Outcome. Am J Cardiol. 2019;124:1340-1348.

13. Lee JM, Choi G, Koo B-K, et al. Identification of High-Risk Plaques Destined to Cause Acute Coronary Syndrome Using Coronary Computed Tomographic Angiography and Computational Fluid Dynamics. JACC Cardiovasc Imaging. 2019;12:1032-1043.

14. Puchner SB, Mayrhofer T, Park J, et al. Differences in the association of total versus local coronary artery calcium with acute coronary syndrome and culprit lesions in patients with acute chest pain: The coronary calcium paradox. Atherosclerosis. 2018;274:251-257.

15. Russo M, Kim HO, Kurihara O, et al. Characteristics of non-culprit plaques in acute coronary syndrome patients with layered culprit plaque. Eur Heart J Cardiovasc Imaging. 2020;21:1421-1430.

16. Kalra DK, Heo R, Valenti V, Nakazato R, Min JK. Role of Computed Tomography for Diagnosis and Risk Stratification of Patients With Suspected or Known Coronary Artery Disease. Arterioscler Thromb Vasc Biol. 2014;34:1144-1154.

17. Mester A, Chițu M, Rat N, et al. CT Determination of Fractional Flow Reserve in Coronary Lesions. Journal of Interdisciplinary Medicine. 2016;1:237-241.

18. Duguay TM, Tesche C, Vliegenthart R, et al. Coronary Computed Tomographic Angiography-Derived Fractional Flow Reserve Based on Machine Learning for Risk Stratification of Non-Culprit Coronary Narrowings in Patients with Acute Coronary Syndrome. Am J Cardiol. 2017:120:1260-1266.

19. Kyhl K, Ahtarovski KA, Nepper-Christensen L, et al. Complete Revascularization Versus Culprit Lesion Only in Patients With ST-Segment Elevation Myocardial Infarction and Multivessel Disease. JACC CardiovasC Interv. 2019;12:721-730

20. Thiele H, Akin I, Sandri M, et al. One-Year Outcomes after PCI Strategies in Cardiogenic Shock. N Engl J Med. 2018;379:1699-1710.

21. Kolte D, Sardar P, Khera S, et al. Culprit Vessel-Only Versus Multivessel Percutaneous Coronary Intervention in Patients With Cardiogenic Shock Complicating ST-Segment-Elevation Myocardial Infarction: A Collaborative Meta-Analysis. Circ Cardiovasc Interv. 2017;10: e005582.

22. Thiele H, Akin I, Sandri M, et al. One-Year Outcomes after PCI Strategies in Cardiogenic Shock. N Engl J Med. 2018;379:1699-1710.

23. Gershlick AH, Banning AS, Parker E, et al. Long-Term Follow-Up of Complete Versus Lesion-Only Revascularization in STEMI and Multivessel Disease. Am J Cardiol. 2019;74:3083-3094.

24. Jeger R, Jaguszewski M, Nallamothu BN, et al. Acute multivessel revascularization improves 1-year outcome in ST-elevation myocardial infarction. Int J Cardiol. 2014;172:76-81.

25. Dziewierz A, Siudak Z, Rakowski T, Zasada W, Dubiel JS, Dudek D. Impact of Multivessel Coronary Artery Disease and Noninfarct-Related Artery Revascularization on Outcome of Patients With ST-Elevation Myocardia Infarction Transferred for Primary Percutaneous Coronary Intervention (from the EUROTRANSFER Registry). Am J Cardiol. 2010;106:342-347.

26. de Waha S, Jobs A, Eitel I, et al. Multivessel versus culprit lesion only percutaneous coronary intervention in cardiogenic shock complicating acute myocardial infarction: A systematic review and meta-analysis. Eur Heart J Acute Cardiovasc Care. 2018;7:28-37.

27. Wald DS, Morris JK, Wald NJ, et al. Randomized Trial of Preventive Angioplasty in Myocardial Infarction. N Engl J Med. 2013;369:1115-1123.

28. Elfaramawy A, Hassan M, Nagy M, ElGuindy A, Elmahdy MF. Impact of fractional flow reserve on decision-making in daily clinical practice: A single center experience in Egypt. Egypt Heart J. 2018;70:161-165.

29. Baumann AAW, Mishra A, Worthley MI, Nelson AJ, Psaltis PJ. Management of multivessel coronary artery disease in patients with non-ST-elevation myocardial infarction: a complex path to precision medicine. Ther Adv Chronic Dis. 2020;11:204062232093852.

30. Piróth Z, Boxma-de Klerk BM, Omerovic E, et al. The Natural History of Nonculprit Lesions in STEMI. JACC Cardiovasc Interv. 2020;13:954-961.

31. Götberg M, Christiansen EH, Gudmundsdottir IJ, et al. Instantaneous Wave-free Ratio versus Fractional Flow Reserve to Guide PCl. N Engl J Med. 2017;376(19):1813-1823.

32. Hatky MA, De Bruyne B, Pontone G, et al. Quality-of-Life and Economic Outcomes of Assessing Fractional Flow Reserve With Computed Tomography Angiography: PLATFORM. J Am Coll Cardiol. 2015;66:23152323

33. Lee $\mathrm{SH}$, Choi KH, Lee JM, et al. Physiologic Characteristics and Clinical Outcomes of Patients With Discordance Between FFR and iFR. JACC. Cardiovascular Interventions. 2019;12(20):2018-2031.

34. Lee JM, Doh J-H, Nam C-W, Shin E-S, Koo B-K. Functional Approach for Coronary Artery Disease: Filling the Gap Between Evidence and Practice. Korean Circ J. 2018;48(3):179.

35. Dey D, Gaur S, Ovrehus KA, et al. Integrated prediction of lesion-specific ischaemia from quantitative coronary CT angiography using machine learning: a multicentre study. Eur Radiol. 2018;28(6):2655-2664. 